\title{
Improving Redox Reversibility and Intermetallic Coupling of Co(III) Alkynyls through
} Tuning of Frontier Orbitals

\author{
Brandon L. Mash, Yiwei Yang, and Tong Ren \\ Department of Chemistry, Purdue University, West Lafayette, IN 47907, USA
}

\section{Table of Contents}

Table S1. Experimental crystal structure details for $[\mathbf{1}]\left(\mathrm{BPh}_{4}\right)_{2}$

Figure S1. Ball and Stick model for $[\mathbf{1}]\left(\mathrm{BPh}_{4}\right)_{2}$

Figure S2. Space fill model for $[\mathbf{1}]\left(\mathrm{BPh}_{4}\right)_{2}$

Figure S4. DPV peak analysis for $[2] \mathrm{Cl}_{2}$

Figure S5. DPV peak analysis for $[3] \mathrm{Cl}_{2}$ .S5

Figure S6. DFT results for $[3]^{2+}$ .S6

Table S2. Bond lengths and angles from DFT

Figure S7. Blank NMR spectrum of $\mathrm{CDCl}_{3}$ .S8

Figure S8. NMR spectrum of $[1] \mathrm{Cl}_{2}$ in $\mathrm{CDCl}_{3}$ S9

Figure S9. NMR spectrum of [2] $\mathrm{Cl}_{2}$ in $\mathrm{CDCl}_{3}$ S10

Figure S10. NMR spectrum of $[3] \mathrm{Cl}_{2}$ in $\mathrm{CDCl}_{3}$ S11

Figure S11. UV-vis spectra for $[\mathbf{1}] \mathrm{Cl}_{2}-[\mathbf{3}] \mathrm{Cl}_{2}$ in $\mathrm{MeCN}$ S11

Figure S12. IR spectra for $[\mathbf{1}] \mathrm{Cl}_{2}-[3] \mathrm{Cl}_{2}$ S12 
Table S1. Experimental details for compound $[1]\left(\mathrm{BPh}_{4}\right)_{2}$. The structure contains 4 independent solvent accessible voids of 1776 Ang3 combined. The residual electron density peaks are not arranged in an interpretable pattern. The structure factors were instead augmented via reverse Fourier transform methods using the SQUEEZE routine (P. van der Sluis \& A.L. Spek (1990). Acta Cryst. A46, 194-201) as implemented in the program Platon. The resultant FAB file containing the structure factor contribution from the electron content of the void space was used in together with the original hkl file in the further refinement. (The FAB file with details of the Squeeze results is appended to this cif file). The Squeeze procedure corrected for 264 electrons within the solvent accessible voids.

\begin{tabular}{|c|c|}
\hline & BLM0028_0m \\
\hline \multicolumn{2}{|l|}{ Crystal data } \\
\hline Chemical formula & $\mathrm{C}_{52} \mathrm{H}_{72} \mathrm{Cl}_{2} \mathrm{Co}_{2} \mathrm{~N}_{8} \cdot 2\left(\mathrm{C}_{24} \mathrm{H}_{20} \mathrm{~B}\right)[+$ solvent $]$ \\
\hline$M_{\mathrm{r}}$ & 1636.35 \\
\hline $\begin{array}{l}\text { Crystal system, space } \\
\text { group }\end{array}$ & Triclinic, $P^{-} 1$ \\
\hline Temperature (K) & 150 \\
\hline$a, b, c(\AA)$ & $14.2358(8), 16.8867(7), 23.2628(14)$ \\
\hline$\alpha, \beta, \gamma\left(^{\circ}\right)$ & 80.4695 (14), $81.1332(14), 79.2906$ (19) \\
\hline$V\left(\AA^{3}\right)$ & $5374.9(5)$ \\
\hline$Z$ & 2 \\
\hline Radiation type & Mo $K \alpha$ \\
\hline$\mu\left(\mathrm{mm}^{-1}\right)$ & 0.40 \\
\hline Crystal size (mm) & $0.42 \times 0.34 \times 0.17$ \\
\hline \multicolumn{2}{|l|}{ Data collection } \\
\hline Diffractometer & $\begin{array}{l}\text { Bruker AXS D8 Quest CMOS } \\
\text { diffractometer }\end{array}$ \\
\hline Absorption correction & $\begin{array}{l}\text { Multi-scan } \\
\text { SADABS 2016/2: Krause, L., Herbst-Irmer, R., Sheldrick G.M. \& Stalke } \\
\text { D., J. Appl. Cryst. } 48 \text { (2015) 3-10 }\end{array}$ \\
\hline$T_{\min }, T_{\max }$ & $0.697,0.746$ \\
\hline $\begin{array}{l}\text { No. of measured, } \\
\text { independent and } \\
\text { observed }[I>2 \sigma(I)] \\
\text { reflections }\end{array}$ & $270036,25738,20708$ \\
\hline$R_{\text {int }}$ & 0.045 \\
\hline$(\sin \theta / \lambda)_{\max }\left(\AA^{-1}\right)$ & 0.659 \\
\hline \multicolumn{2}{|l|}{ Refinement } \\
\hline $\begin{array}{l}R\left[F^{2}>2 \sigma\left(F^{2}\right)\right] \\
w R\left(F^{2}\right), S\end{array}$ & $0.046,0.132,1.04$ \\
\hline No. of reflections & 25738 \\
\hline No. of parameters & 1032 \\
\hline H-atom treatment & H-atom parameters constrained \\
\hline
\end{tabular}


\begin{tabular}{|l|l|}
\hline$\left.\Delta\rangle_{\max }, \Delta\right\rangle_{\min }\left(\mathrm{e} \AA^{-3}\right)$ & $0.63,-0.70$ \\
\hline
\end{tabular}

Computer programs: Apex3 v2018.1-0 (Bruker, 2018), SAINT V8.38A (Bruker, 2016), SHELXS97

(Sheldrick, 2008), SHELXL2018/3 (Sheldrick, 2015, 2018), SHELXLE Rev937 (Hübschle et al., 2011).

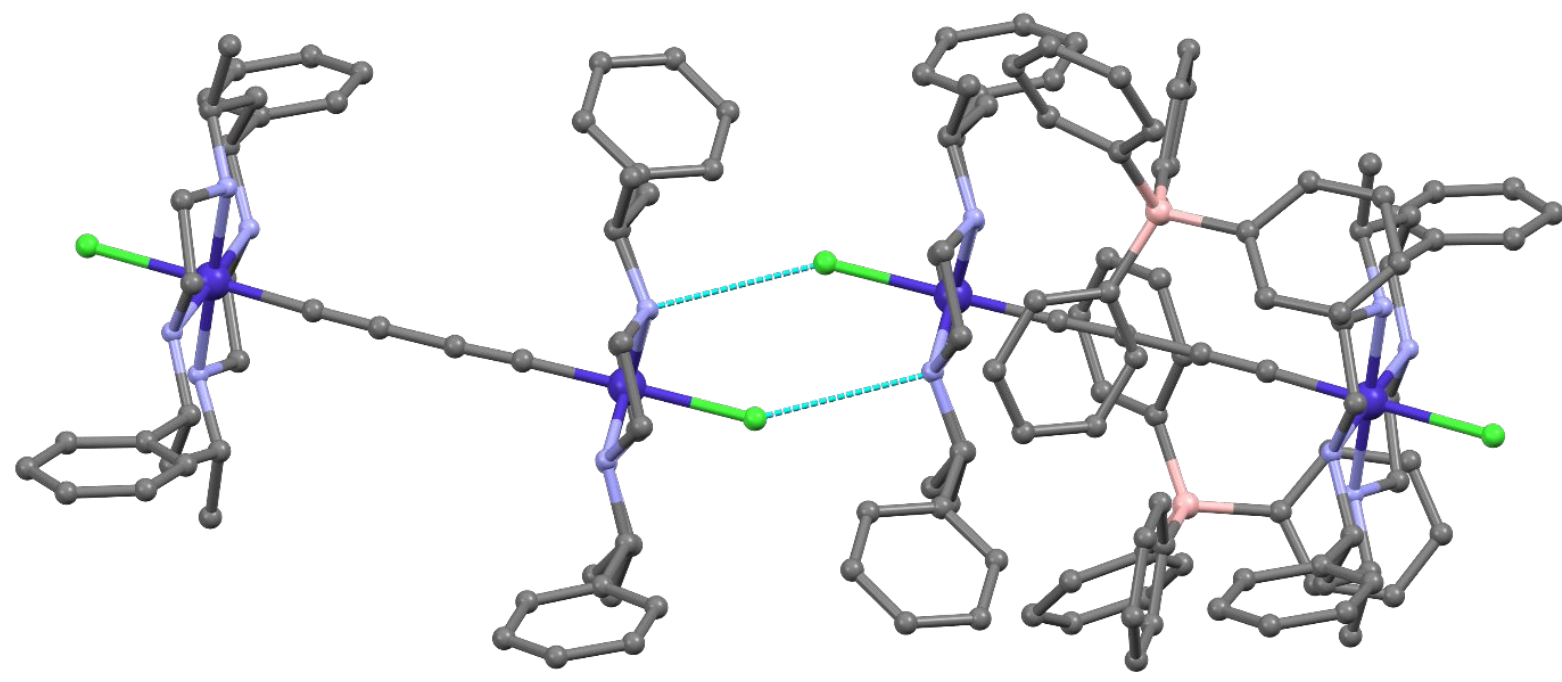

Figure S1. A ball and stick structural plot of $[1]\left(\mathrm{BPh}_{4}\right)_{2}$ is shown. Hydrogen atoms are omitted for clarity. Both cationic structures are symmetrically equivalent. The hydrogen bonding along the ends of each molecule as well as the positioning of the tetraphenylborate anion allow a stable packing structure. The longer alkynyl capping ligands for $[2]^{2+}$ and $[3]^{2+}$ prevent the possibility of hydrogen bonding, making crystallization difficult.

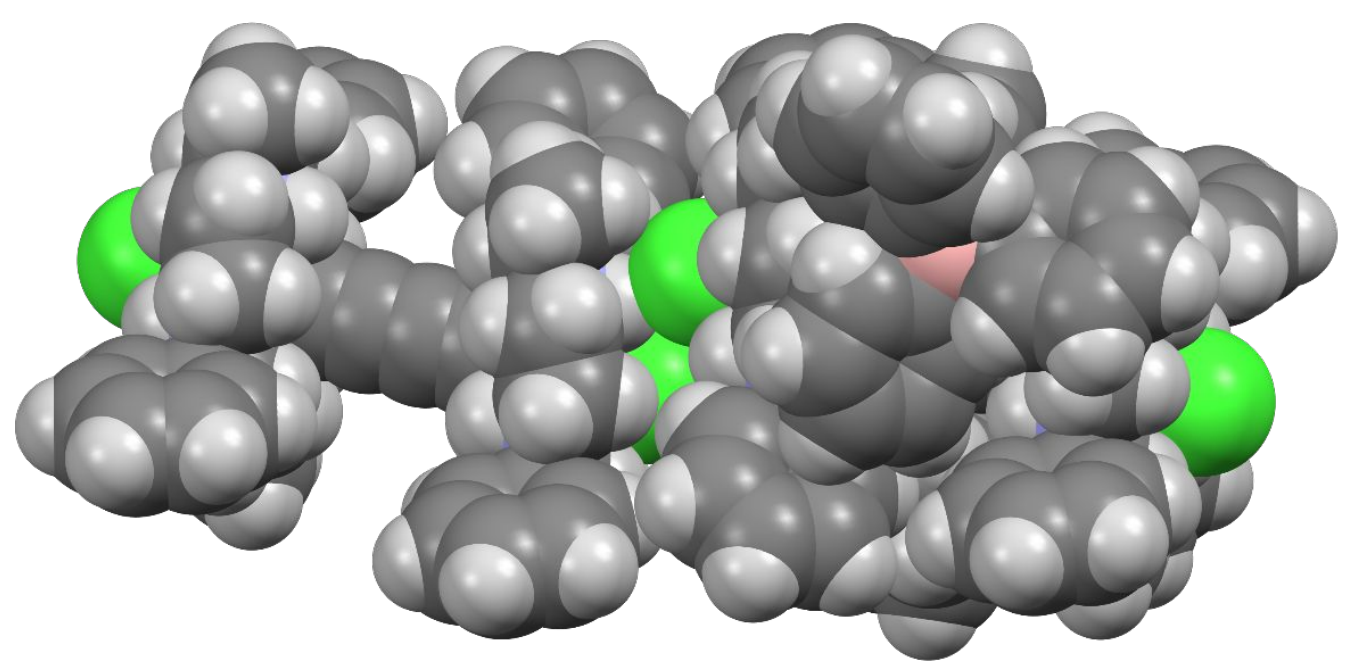

Figure S2. A spacefill model of $[\mathbf{1}]\left(\mathrm{BPh}_{4}\right)_{2}$ with the same view as in the previous figure is shown. The space around the alkynyl bridge does not allow for most solvent molecules to fill. 


\section{Peak Analysis}

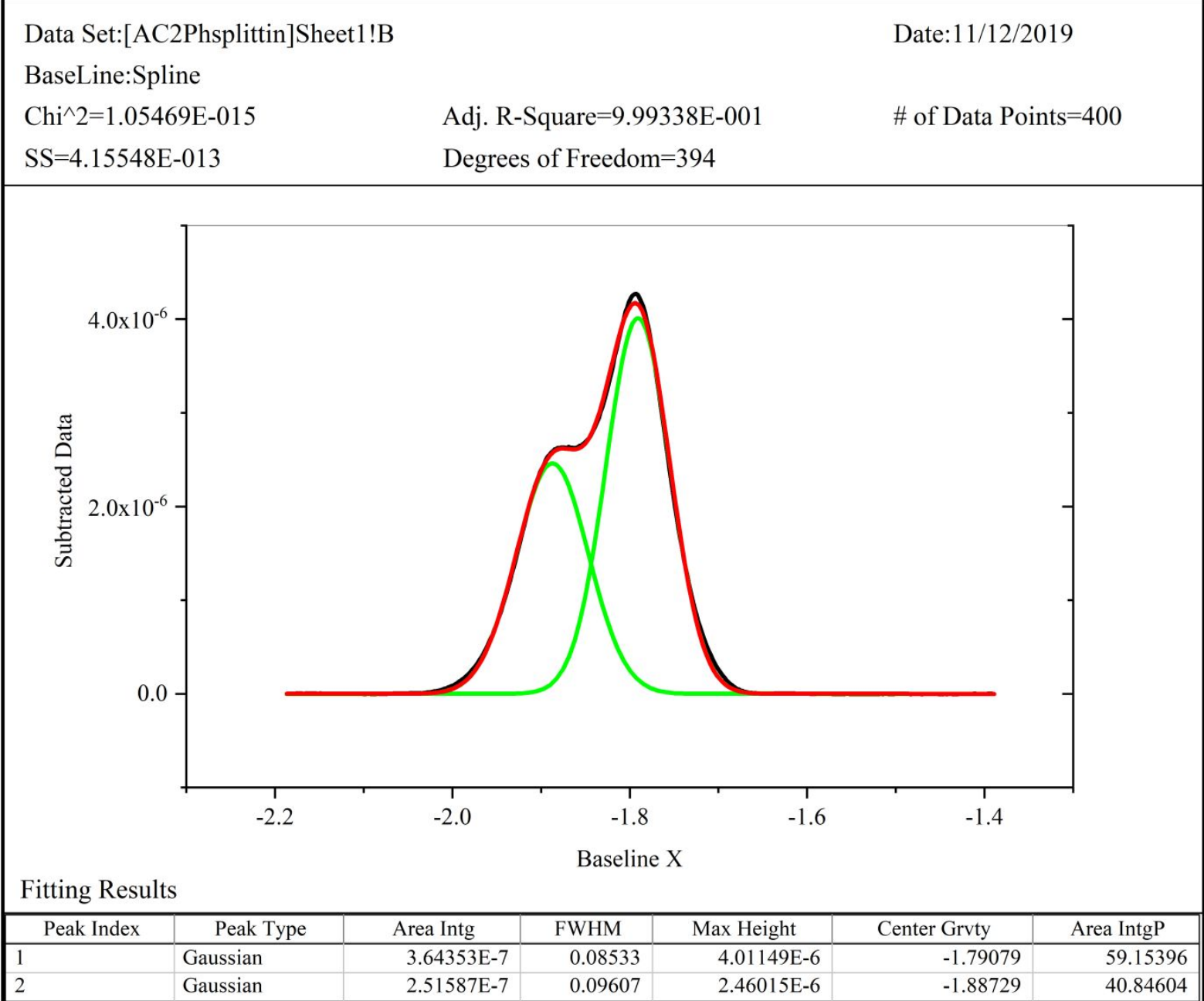

Figure S3. Peak analysis for differential pulse voltammogram of [2]Cl 2 . Data was collected using $1.0 \mathrm{mM}[2] \mathrm{Cl}_{2}$ in a $0.1 \mathrm{M} \mathrm{Bu}_{4} \mathrm{NPF}_{6} \mathrm{MeCN}$ solution. Data was collected following the parameters described by Richardson and Taube (Inorg. Chem. 1981, 20 (4), 1278-1285.). 


\section{Peak Analysis}

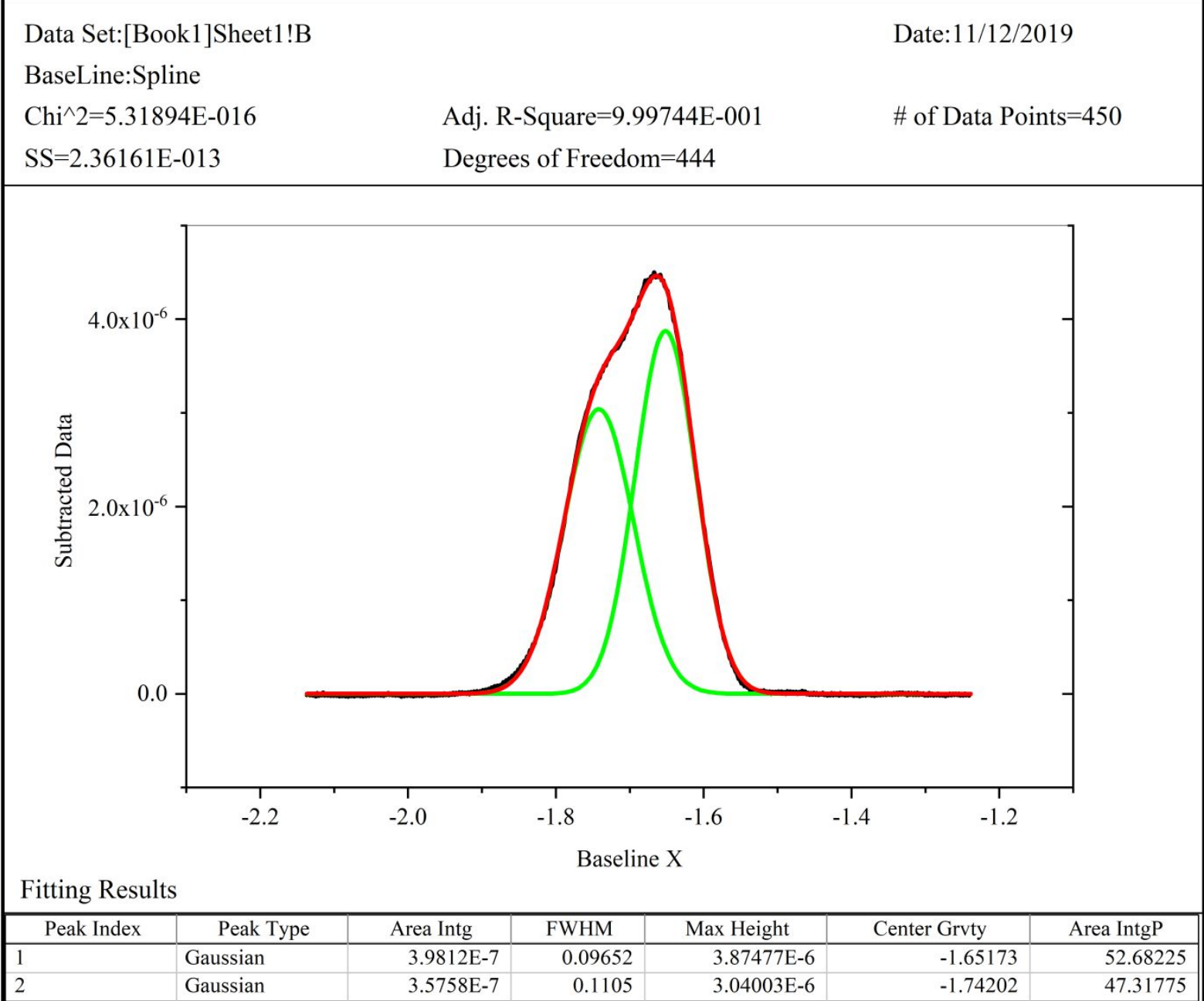

Figure S4. Peak analysis for differential pulse voltammogram of [2]Cl 2 . Data was collected using $1.0 \mathrm{mM}[2] \mathrm{Cl}_{2}$ in a $0.1 \mathrm{M} \mathrm{Bu}_{4} \mathrm{NPF}_{6} \mathrm{MeCN}$ solution. Data was collected following the parameters described by Richardson and Taube (Inorg. Chem. 1981, 20 (4), 1278-1285.). 


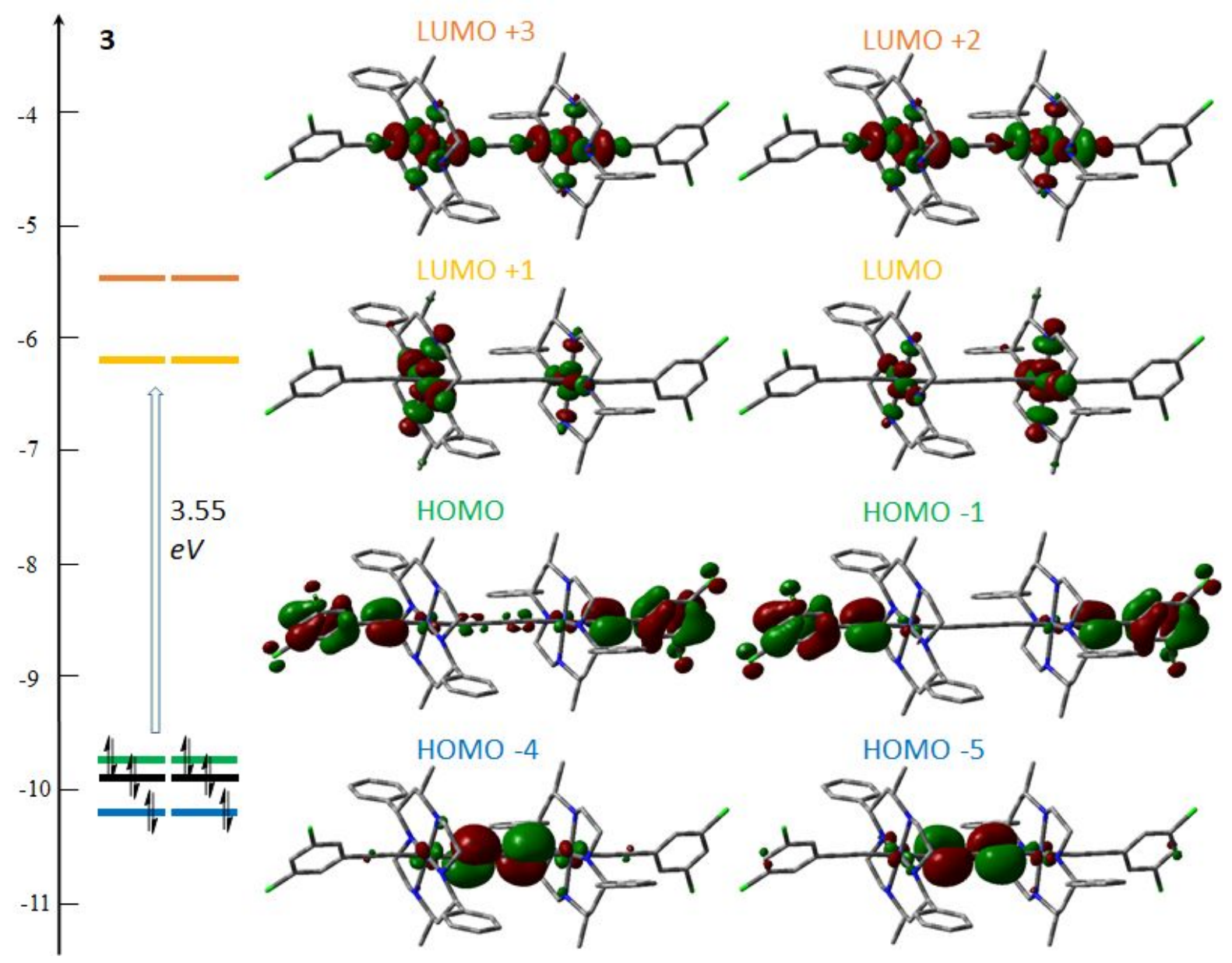

Figure S5. Molecular orbital diagram for $[3]^{2+}$ from DFT calculations. The isovalue of the contour plots was set at 0.03 . 
Table S2. Relevant bond lengths $(\AA)$ and angles $\left(^{\circ}\right)$ for $[\mathbf{1}]^{2+},[2]^{2+}$, and $[3]^{2+}$ from DFT calculations. Axial1 and Axial2 refer to the atom coordinated to cobalt opposite the bridging ligand.

\begin{tabular}{cccc}
\hline & {$[\mathbf{1}]^{2+}$} & {$[\mathbf{2}]^{2+}$} & {$[\mathbf{3}]^{2+}$} \\
\hline Co1-N1 & 2.064 & 2.024 & 2.025 \\
Co1-N2 & 2.024 & 2.036 & 2.036 \\
Co1-N3 & 2.016 & 2.026 & 2.026 \\
Co1-N4 & 2.037 & 2.033 & 2.034 \\
Co2-N5 & 2.015 & 2.026 & 2.026 \\
Co2-N6 & 2.037 & 2.033 & 2.033 \\
Co2-N7 & 2.026 & 2.024 & 2.025 \\
Co2-N8 & 2.024 & 2.037 & 2.036 \\
Co1-Axial1 & 2.318 & 1.942 & 1.943 \\
Co2-Axial2 & 2.319 & 1.942 & 1.943 \\
Co1-C1 & 1.914 & 1.963 & 1.961 \\
Co2-C4 & 1.914 & 1.963 & 1.961 \\
C1-C2 & 1.236 & 1.238 & 1.238 \\
C2-C3 & 1.379 & 1.380 & 1.380 \\
C3-C4 & 1.236 & 1.238 & 1.238 \\
Axial1-Co1-C1 & 179.26 & 179.93 & 179.97 \\
Axial2-Co2-C4 & 179.17 & 179.93 & 179.95 \\
Co1-C1-C2 & 175.82 & 175.06 & 175.09 \\
Co2-C4-C3 & 176.09 & 175.06 & 175.02 \\
\hline
\end{tabular}




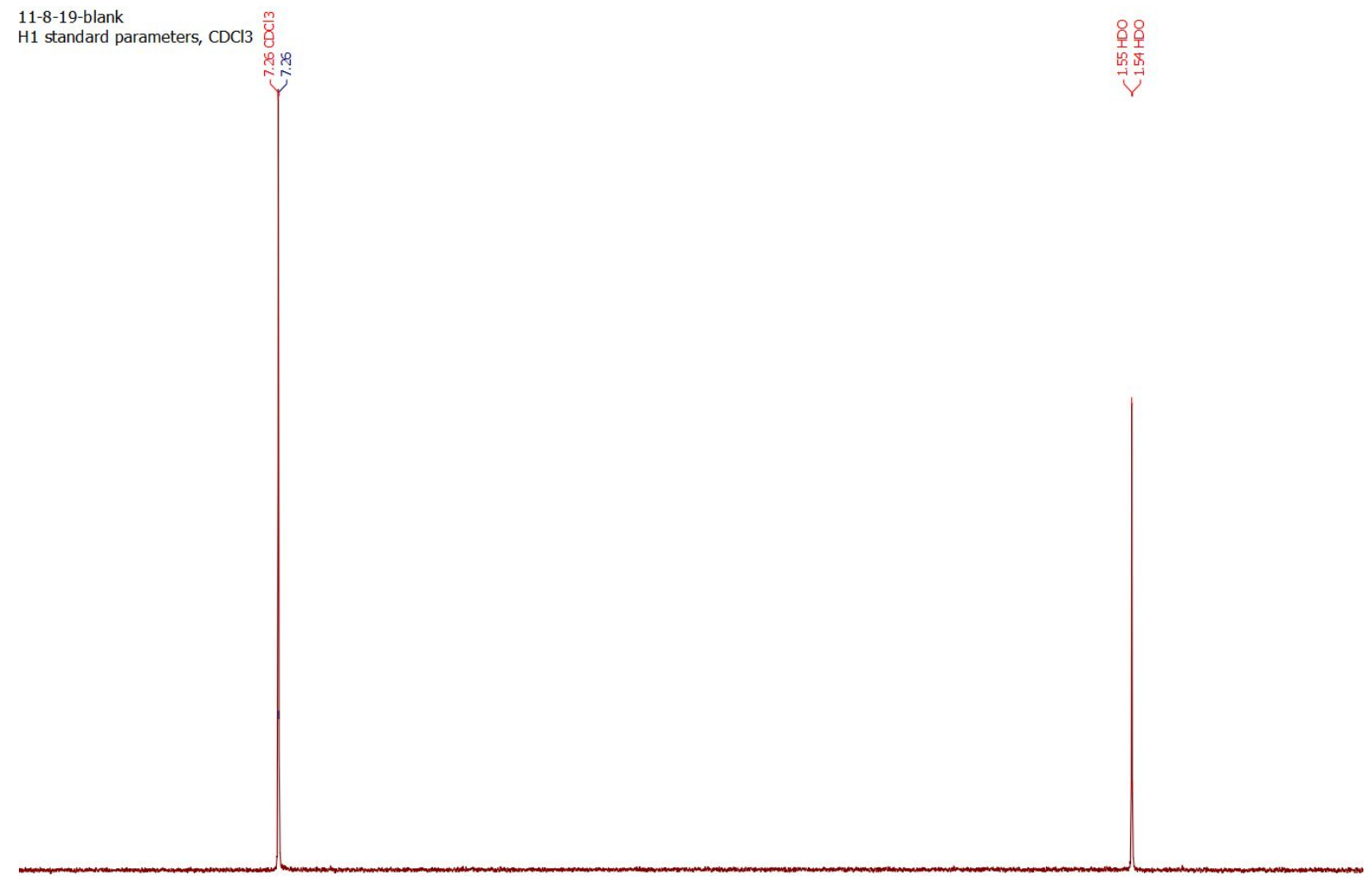

\begin{tabular}{lllllllllllllllllll}
\hline 0 & 8.5 & 8.0 & 7.5 & 7.0 & 6.5 & 6.0 & 5.5 & 5.0 & $\begin{array}{c}1 \\
\mathrm{f} 1(\mathrm{ppm})\end{array}$ & 4.0 & 3.5 & 3.0 & 2.5 & 2.0 & 1.5 & 1.0 & 0.5 & 0.
\end{tabular}

Figure S6. Blank ${ }^{1} \mathrm{HNMR}$ spectrum of $\mathrm{CDCl}_{3}$ collected at the same time as compounds $[\mathbf{1}] \mathrm{Cl}_{2}-[3] \mathrm{Cl}_{2} \cdot \mathrm{H}_{2} \mathrm{O}$ is present in the solvent. 


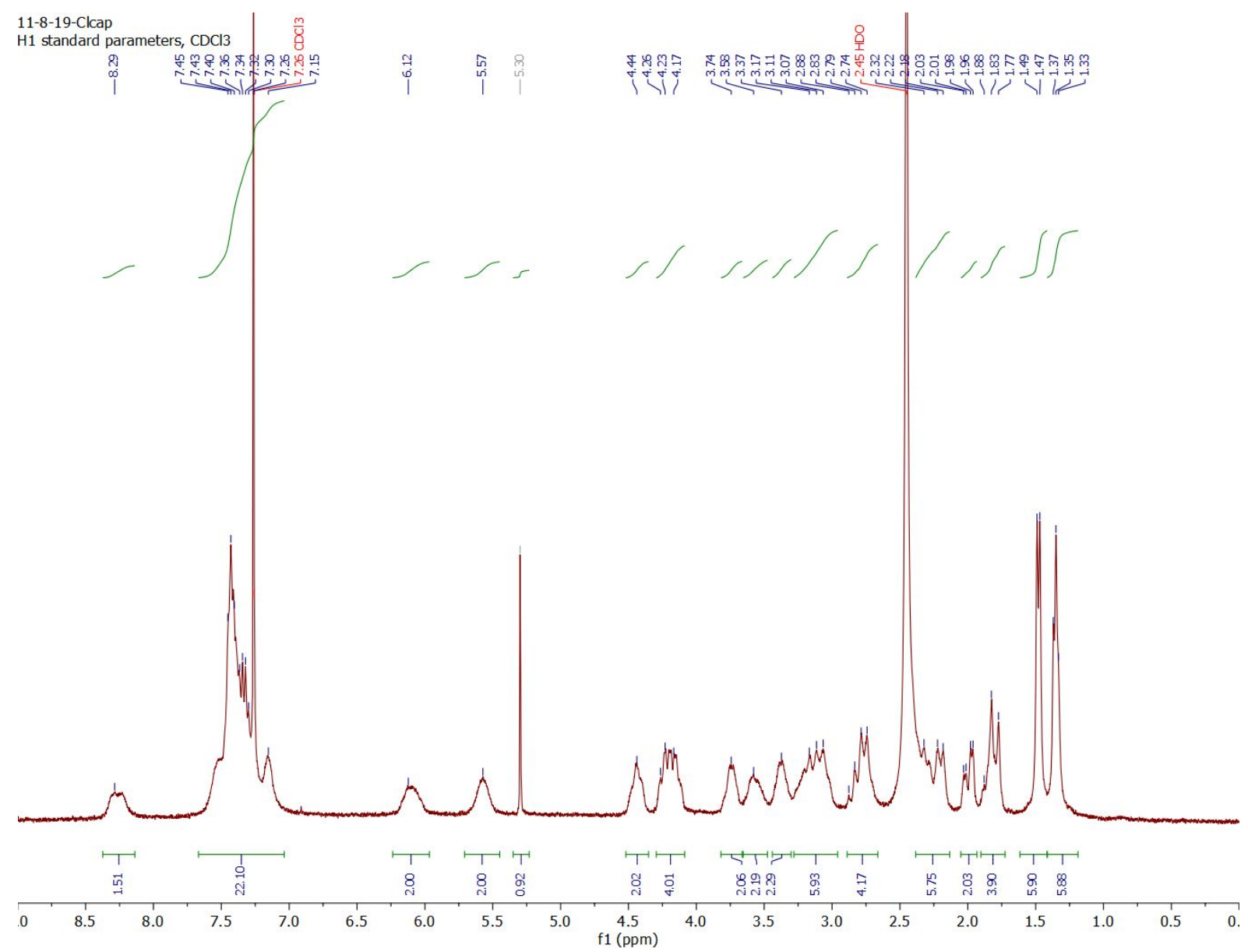

Figure S7. ${ }^{1} \mathrm{HNMR}$ spectrum of $[1] \mathrm{Cl}_{2}$ in $\mathrm{CDCl}_{3}$. $\mathrm{H}_{2} \mathrm{O}$ has shifted from the blank and $\mathrm{CH}_{2} \mathrm{Cl}_{2}$ (5.30 ppm) is present after vacuum drying the compound. 


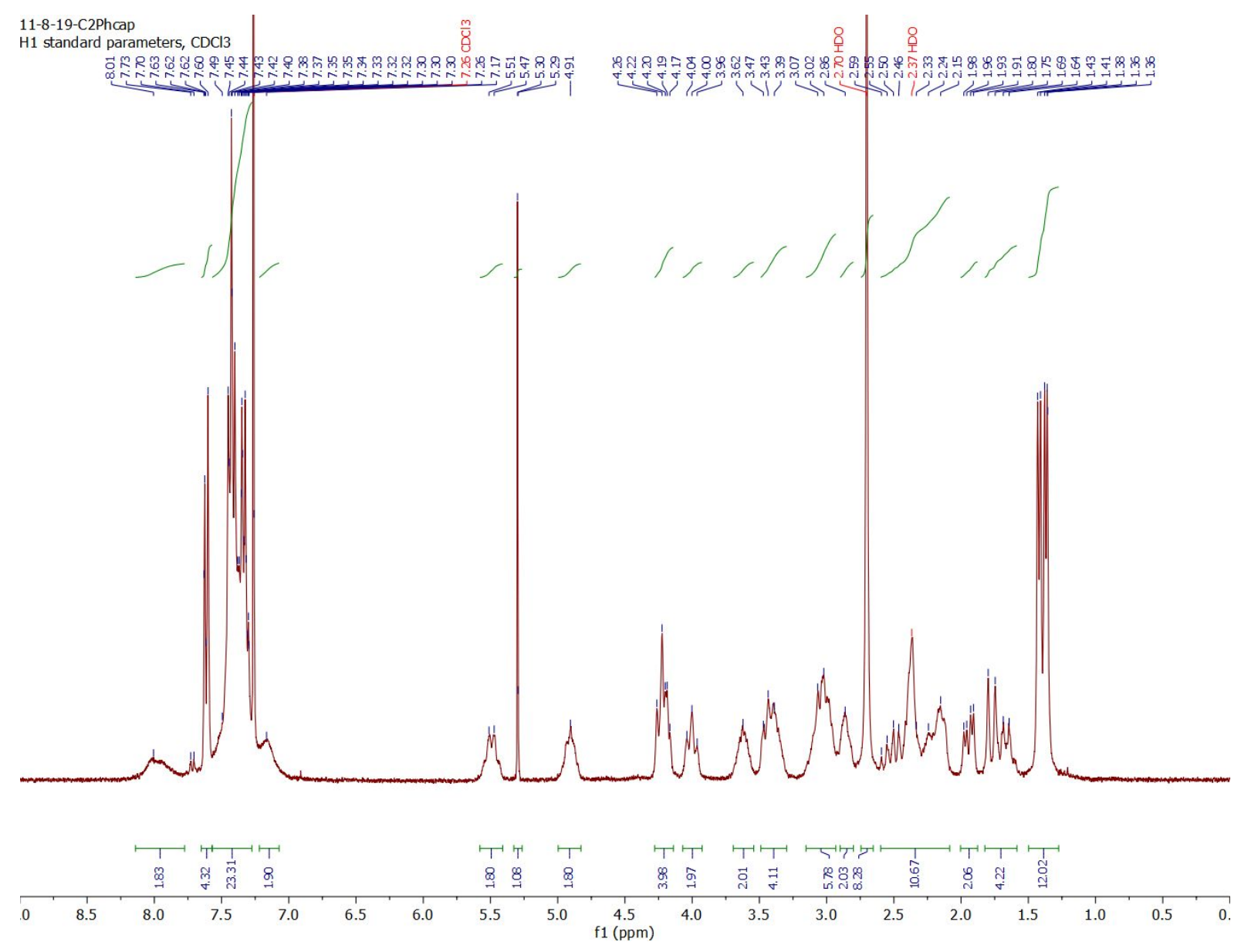

Figure S8. ${ }^{1} \mathrm{HNMR}$ spectrum of $[2] \mathrm{Cl}_{2}$ in $\mathrm{CDCl}_{3} . \mathrm{H}_{2} \mathrm{O}$ has shifted from the blank and $\mathrm{CH}_{2} \mathrm{Cl}_{2}$ $(5.30 \mathrm{ppm})$ is present after vacuum drying the compound. 


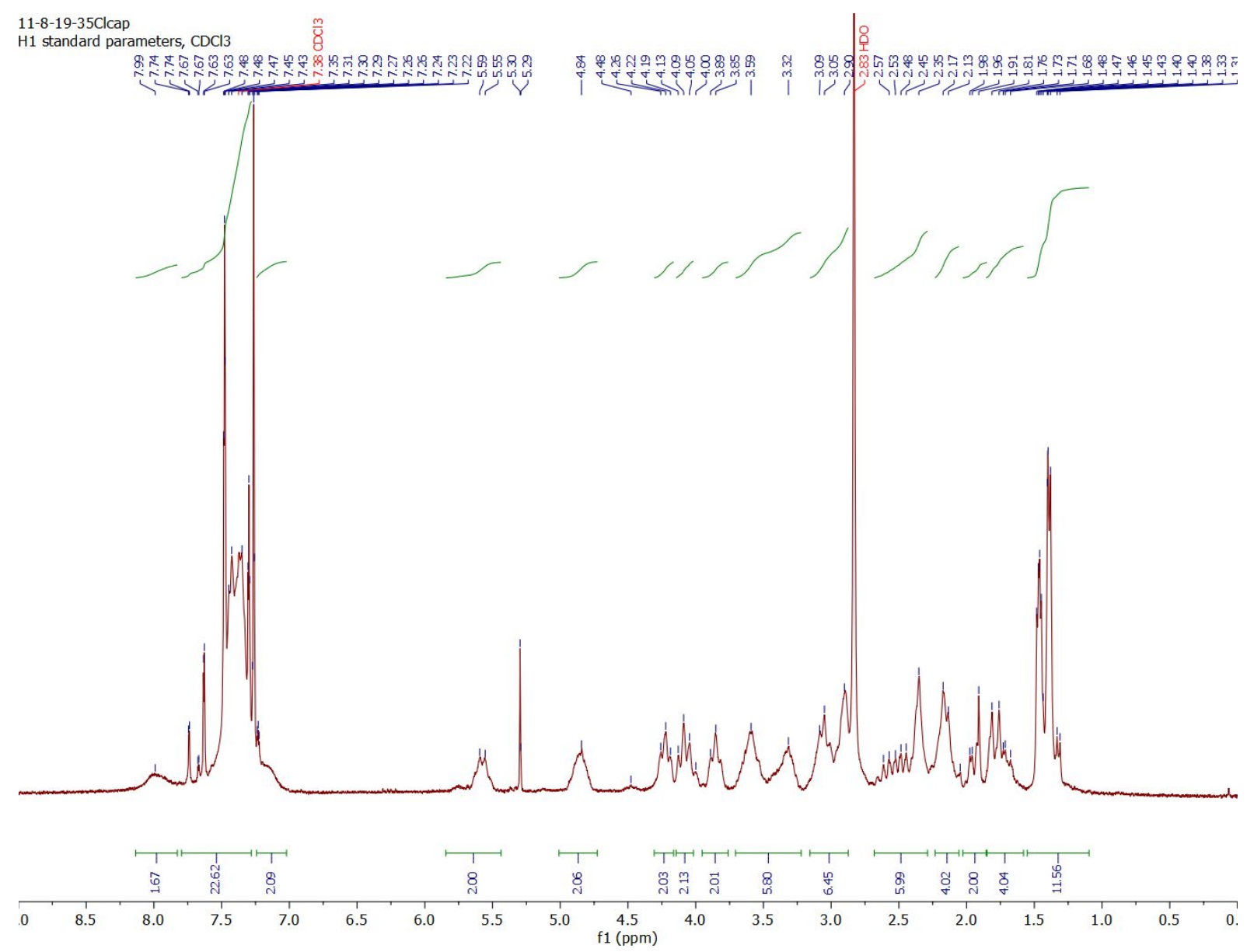

Figure S9. ${ }^{1} \mathrm{HNMR}$ spectrum of $[3] \mathrm{Cl}_{2}$ in $\mathrm{CDCl}_{3} . \mathrm{H}_{2} \mathrm{O}$ has shifted from the blank and $\mathrm{CH}_{2} \mathrm{Cl}_{2}$ $(5.30 \mathrm{ppm})$ is present after vacuum drying the compound.
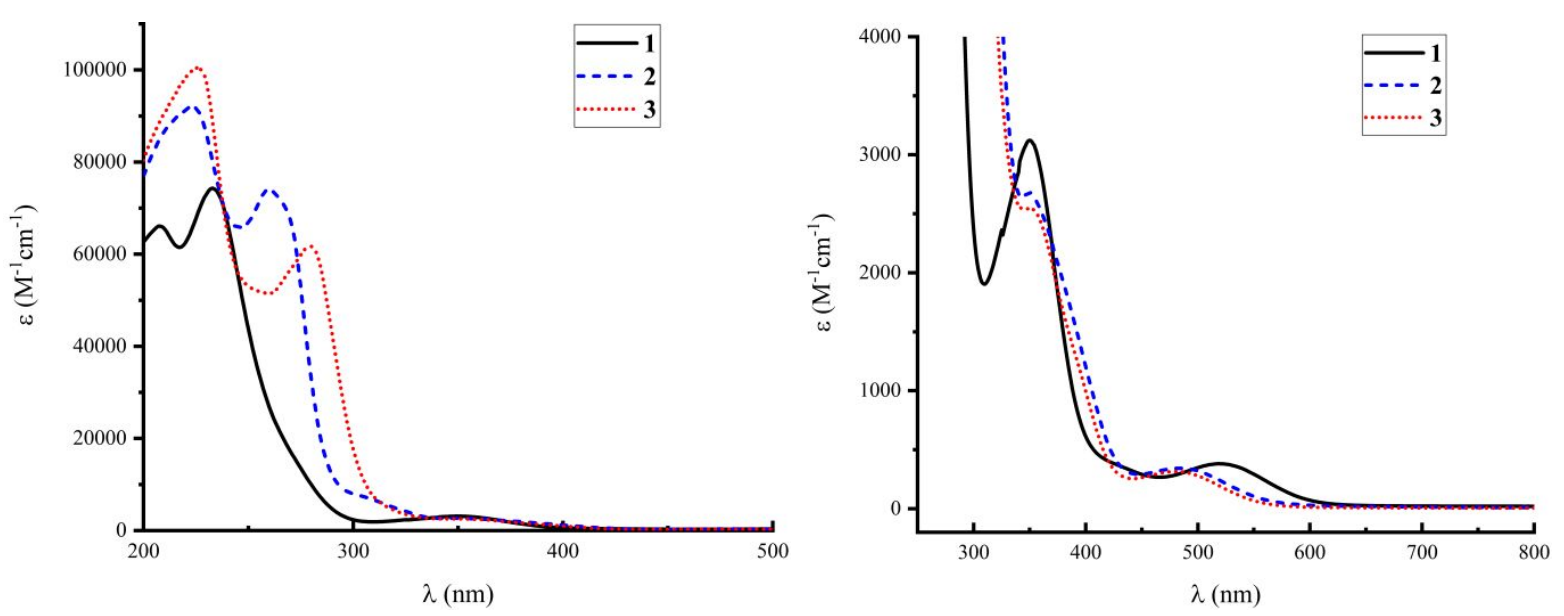

Figure S10. Electronic absorption spectra for $[1] \mathrm{Cl}_{2},[2] \mathrm{Cl}_{2}$, and $[3] \mathrm{Cl}_{2}$ in neat $\mathrm{MeCN}$ solutions. The stronger UV absorptions are shown on the left while the weak metal-based absorptions are shown on the right. 


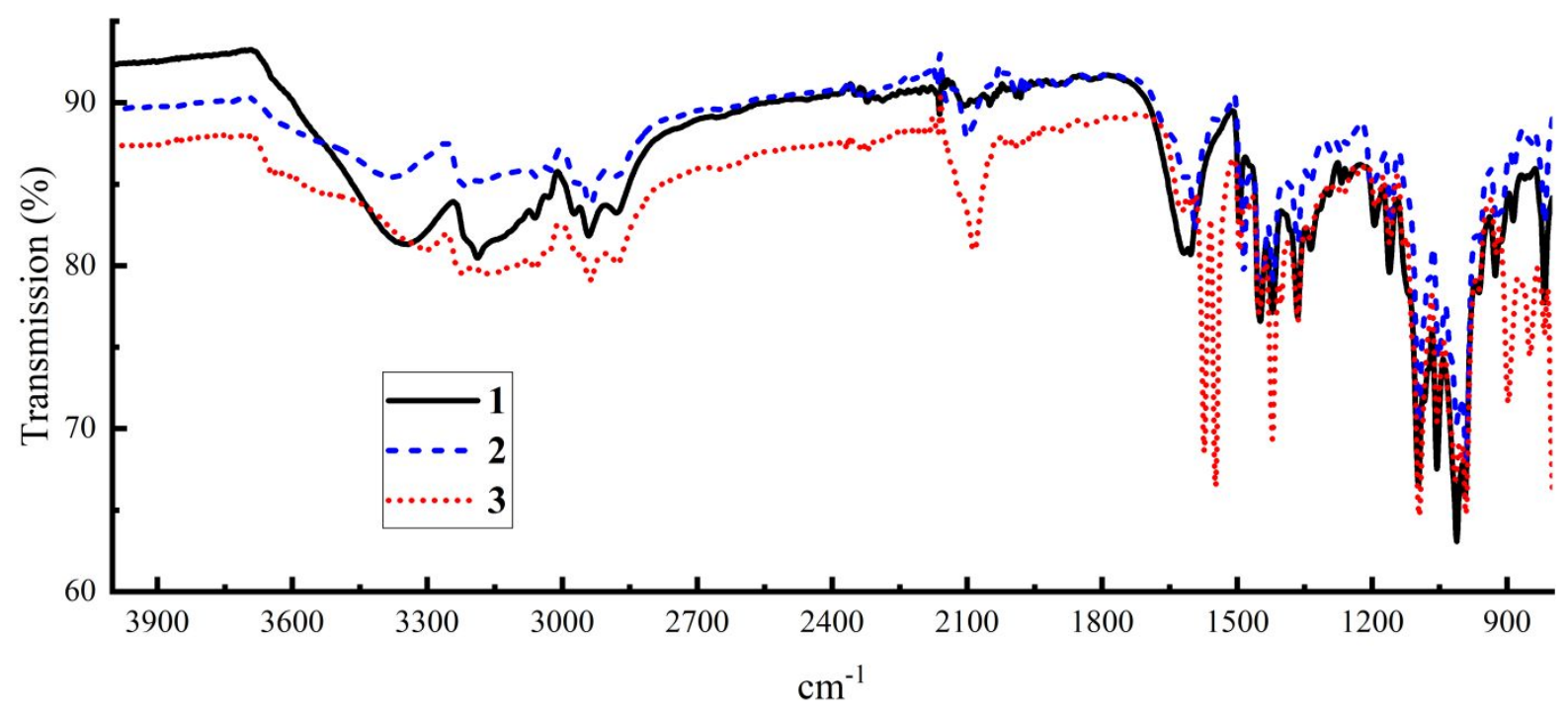

Figure S11. IR spectra for $[1] \mathrm{Cl}_{2},[2] \mathrm{Cl}_{2}$, and $[3] \mathrm{Cl}_{2}$. 